\title{
Comparison of motor coach exhaust emissions in real operating conditions for different testing procedures
}

\author{
Dawid Gallas ${ }^{1,{ }^{*}}$, Jerzy Merkisz ${ }^{2}$, Maciej Andrzejewski ${ }^{1}$, Sylwin Tomaszewski ${ }^{1}$, Jan Strzemkowski $^{1}$, and Stepan Kinter $^{3}$ \\ ${ }^{1}$ Lukasiewicz Research Network - Rail Vehicles Institute “TABOR”, Poznan ul. Warszawska 181, Poland \\ ${ }^{2}$ Poznan University of Technology, Institute of Combustion Engines and Transport, Poznan ul. Piotrowo 3, Poland \\ ${ }^{3}$ DNURT, Lviv branch, I. Blazhkevich St. 12-a, Lviv, 79052,Ukraine
}

\begin{abstract}
The article discusses the results of applying real driving emissions (RDE) testing methods in measuring the exhaust emissions of a passenger rail vehicle. Portable Emissions Measuring Systems (PEMS) were used to measure the exhaust emissions from a motor coach in real operation, performed on a test track for selected drive cycle parameters. The road emission values of exhaust components have been calculated and compared to road vehicles and road exhaust emission limits based on the legal norms. The assessment was concluded with a comparison of the environmental cost, in terms of exhaust emissions, of transporting passengers using the tested rail vehicle relative to alternative road transport, based on measurements in real operating conditions.
\end{abstract}

\section{Introduction}

With the increasing awareness of the problems caused by $\mathrm{CO}_{2}$ emissions produced by the transport sector, along with other toxic compounds emitted from spark and compression ignition combustion engines the focus placed on mitigating the most environmentally harmful aspects of the transport sector. Road transport has been the precursor to these measures, with increasingly demanding exhaust emission limits of harmful combustion products as well as testing and implementing new emission measuring devices and techniques into the legal framework of type approval. The most recent result of these efforts was the introduction of RDE (Real Driving Emissions) testing for road vehicles. This was the response of lawmakers to the problem of stationary dynamometer tests not being sufficiently representative of the actual exhaust emissions generated by vehicles. Spurred onwards by controversy caused by the defeat devices found in many brands of road vehicles meant to cheat the testing procedure, it culminated in the Euro 6 emission norm being a combination of both a WLTC (Worldwide harmonized Light vehicles Test Cycles) dynamometer test along with an RDE test in real driving conditions. Thus the new emission norms were defined as NTE (Not To Exceed) limit but allowed deviation for RDE test results based on the "conformity factor".

The emission norms for rail vehicles differ from the norms for road vehicles, but the combustion engines and exhaust aftertreatment technologies are similar for these two groups of vehicles [1,2]. This, in turn, indicates a certain likelihood of the methods and limits pioneered for road vehicles to be eventually incorporated in similar legal provisions for rail vehicles and other NRMM (Non-
Road Mobile Machinery). The current Stage V emission norm provides just two different sets of emission limit values based on two large categories of rail vehicles. This does not allow the norms to take into account the often widely different operating characteristics of various rail vehicles performing different types of work. In general, a specific exhaust emission values are used as limits, but this does not accurately represent the ecological costs of transporting passengers in passenger trains or motor coaches. Road vehicle limits, on the other hand, embrace the different natures and goals of different types of vehicles, resulting in specific emission values being used for measuring the ecological indicators of heavy and long-haul vehicles while for light and passenger vehicles road emission values are used. This allows for a more direct assessment of the mass of a given exhaust component being emitted per kilometer of travel, which can be further also divided by the number of passengers transported to obtain the emission per person per kilometer. These calculated values allow for a much easier emissions comparison, not only between different cars, but also between different modes of transport. In terms of mass passenger transport a direct comparison between rail passenger vehicles (motor coach or tram) and buses should be considered. Especially since the most modern urban bus solutions to improve their fuel economy and ecological indicators [3] have been the direct result of increasing the reliance of RDE testing for road vehicles belonging to the public transport sector [4, 5]. A direct comparison would serve as a guideline for municipalities in choosing between the investments in different public transport technologies.

Corresponding author: d.gallas@tabor.com.pl 


\subsection{Test object and apparatus}

The vehicle used for testing was a LINK motor coach (Fig. 1), powered by two diesel engines, each with a rated power of $390 \mathrm{~kW}$ and a swept volume of $13 \mathrm{dm}^{3}$. The tests were performed using only one of the engines in order to ensure results reliability.

The measuring apparatus was a PEMS type device AxionR/S+ produced by GLOBAL MRV (Fig. 2). This device was equipped with two exhaust gas analyzers working together to assess the exhaust emissions of $\mathrm{CO}_{2}$, $\mathrm{CO}, \mathrm{HC}$, and NO. Additionally, the analyzer measured the $\mathrm{O}_{2}$ content in the exhaust gas, but this data was used only for results validation. The PEMS device used an array of devices for measuring exhaust emissions such as Non-Dispersive Infrared (NDIR) and an electrochemical sensor. An airtight connection between the vehicle exhaust pipe and the flowmeter was created, and a probe was attached to a side channel to allow the flow of the exhaust gas into the AxionR/S+ analyzers (Fig. 3). The exhaust gas was transported with a heated line, to prevent condensation of volatile components on its walls. It should be noted that these devices and method are commonly applied to RDE exhaust emissions testing for road vehicles, as well as NRMM. The exhaust emission values presented further in the article are a result of using a road vehicle RDE testing and assessment methods for a rail vehicle in an effort to increase the comparability of the obtained data.

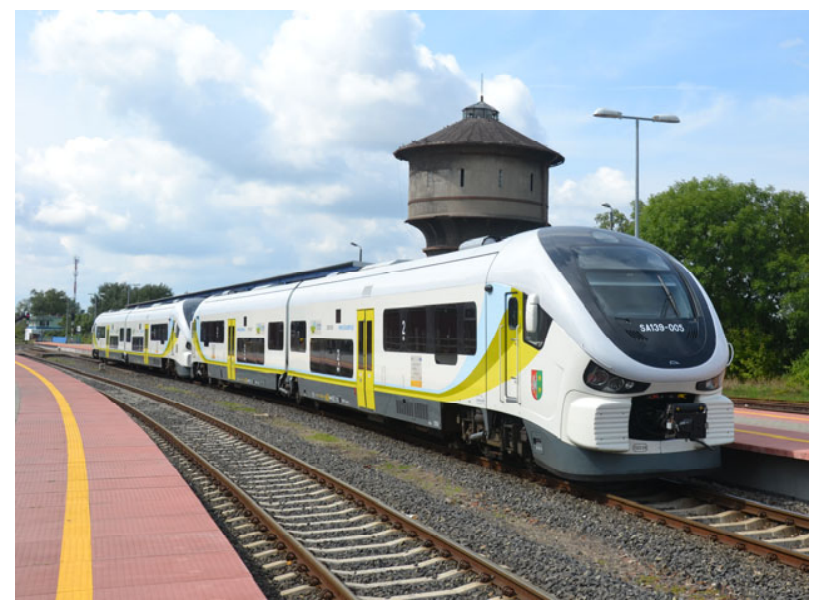

Fig. 1. The tested motor coach vehicle

The whole system was set up in such a way as to ensure there would be no risk of the added devices touching the above catenary, or extending outside of the permitted track gouge. The systems mounted on the roof were tightly secured to the vehicle with the use of special belts and suction pads.

\subsection{Test method}

The test drive was performed on a special track designated for testing rail vehicles in motion. The track was $7.7 \mathrm{~km}$ long and consisted of turns with radii of 600 , 700,800 and 900 meters. The maximum travel speed on the track was $160 \mathrm{~km} / \mathrm{h}$, but in the performed test drives only speeds of up to $100 \mathrm{~km} / \mathrm{h}$ were used.

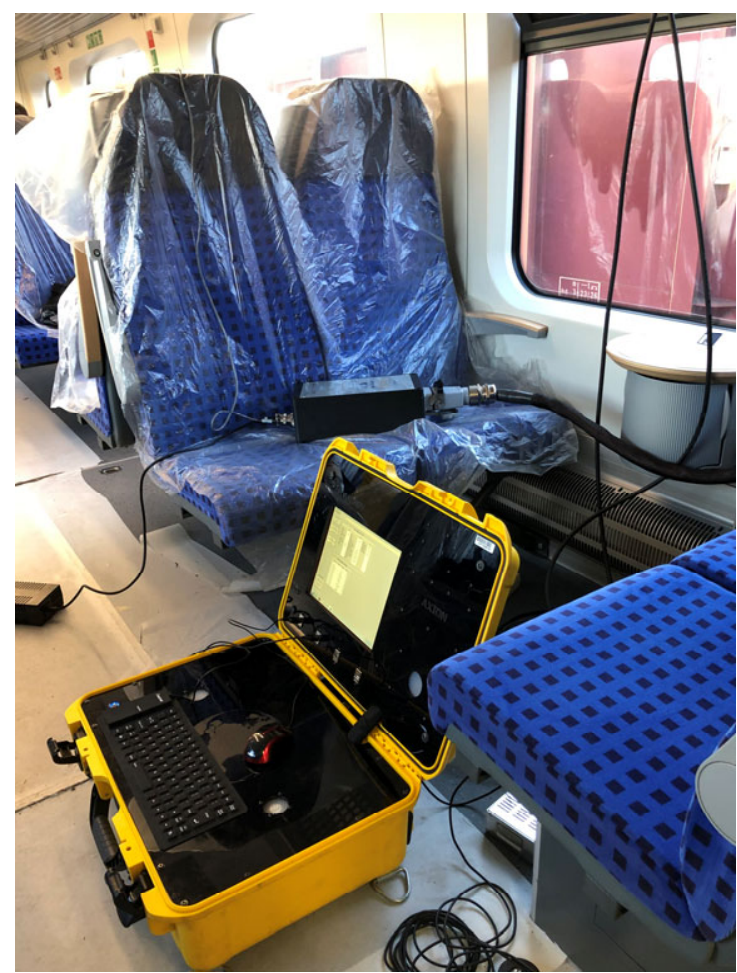

Fig. 2. AxionR/S+ device setup inside the motor coach, with a probe connected to the exhaust pipe

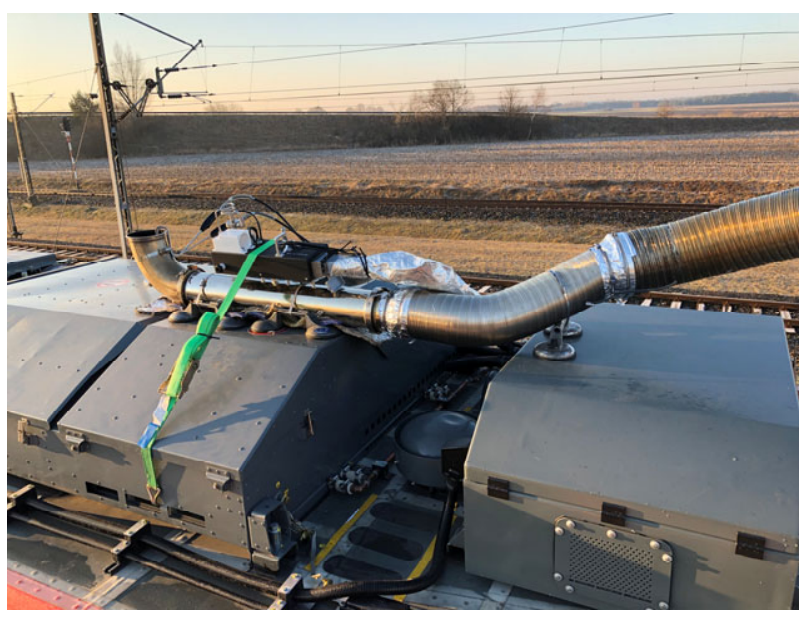

Fig. 3. Flowmeter mounted on the roof of the vehicle and the heated line for gas sampling

The exhaust emission data was gathered and processed in order to obtain emission values for $\mathrm{CO}_{2}, \mathrm{CO}, \mathrm{HC}$, and NO. These results were compared to the road vehicles exhaust emission norms (Table 1), for further assessment of the motor coach ecological indicators. Do note that the particulate matter emissions are not considered in this research. Motion and speed of the vehicle were calculated based on the obtained GPS data.

Two drive cycles were performed to assess the impact of travel speed limit on the exhaust emissions. Both drives were done over the same route but the maximum travel speed limit for Drive 1 was $70 \mathrm{~km} / \mathrm{h}$, while for Drive 2 it was $100 \mathrm{~km} / \mathrm{h}$. This allowed to numerically reflect the impact of travel speed on the vehicle ecological indicators. 


\section{Results}

The exhaust emission results for the tested motor coach were presented as emitted mass of a compound per second and as road emissions (mass of compound emitted per $\mathrm{km}$ of travel). Figures 4 and 5 (previous page) show the measured exhaust emission results from Drives 1 and 2 respectively for carbon dioxide $\left(\mathrm{CO}_{2}\right)$, carbon monoxide (CO), hydrocarbons (HC) and nitrogen oxide (NO).

The total mass of each measured exhaust component emitted during each of the two drive cycles (1 and 2) was then used to determine the road emissions of the tested vehicle in real operation (Fig. 6). The change of the road emission value between Drive 1 and Drive 2 was also presented as a percentage of the value for Drive 1 (Fig. 7).

The road exhaust emission values were then divided by the number of passengers for a fully loaded vehicle, which in the case of a LINK motor coach is about 126 passenger seats in each vehicle set, excluding the driver. It should be noted, that in some cases the number of passengers may exceed the seat limit, however, allowing more passengers onboard to remain standing.

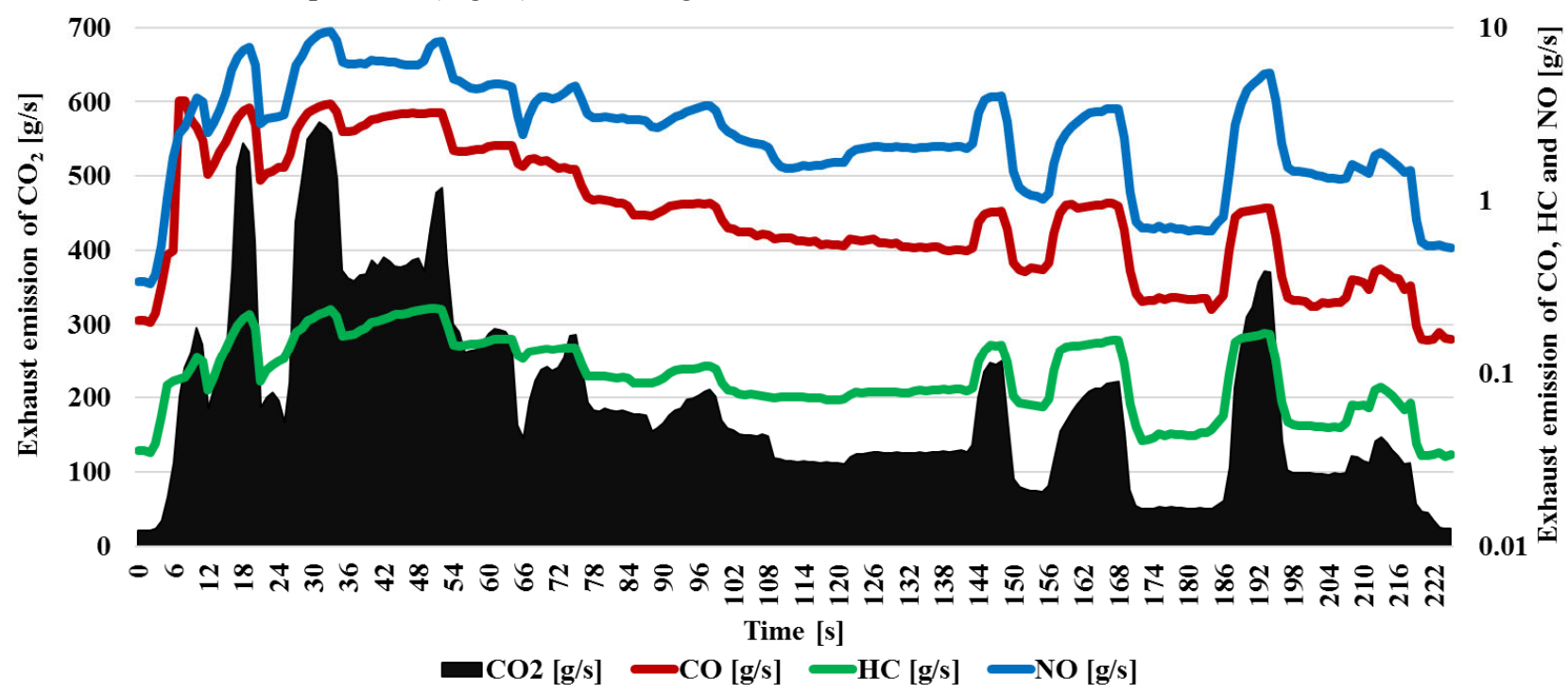

Fig. 4. Exhaust emissions represented in time for Drive 1

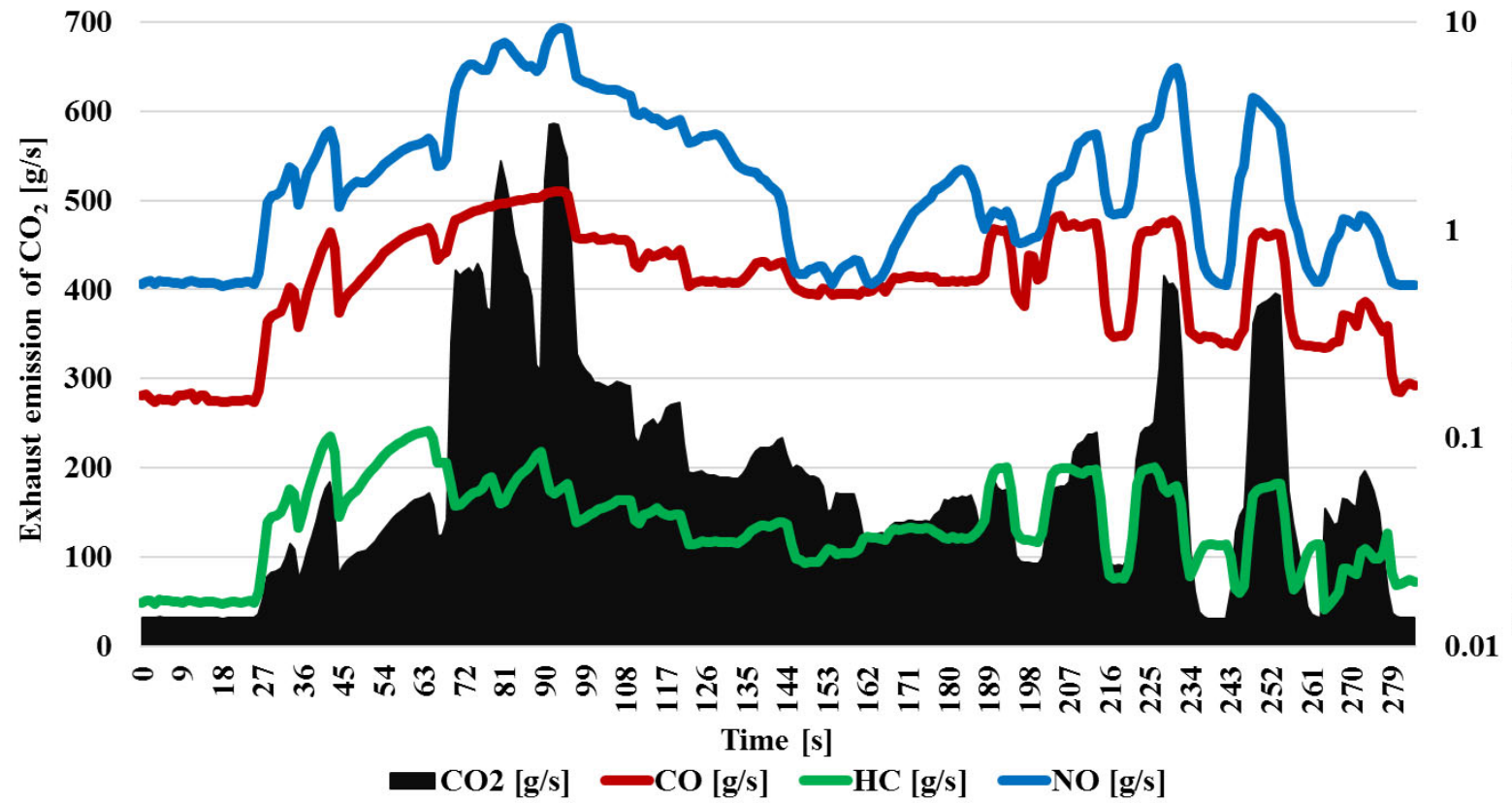

Fig. 5. Exhaust emissions represented in time for Drive 2 
Table 1. Exhaust emission limits for light passenger cars

\begin{tabular}{|c|c|c|c|c|c|c|}
\hline Name & $\begin{array}{c}\text { In effect } \\
\text { since }\end{array}$ & $\begin{array}{c}\mathbf{C O} \\
{[\mathbf{g} / \mathbf{k m}]}\end{array}$ & $\begin{array}{c}\mathbf{H C}+\mathbf{N O x} \\
{[\mathbf{g} / \mathbf{k m}]}\end{array}$ & $\begin{array}{c}\mathbf{N O x} \\
{[\mathbf{g} / \mathbf{k m}]}\end{array}$ & $\begin{array}{c}\mathbf{P M} \\
{[\mathbf{g} / \mathbf{k m}]}\end{array}$ & $\begin{array}{c}\mathbf{P N} \\
{[\mathbf{1} / \mathbf{k m}]}\end{array}$ \\
\hline Euro 3 & Jan. 2001 & 0.66 & 0.56 & 0.50 & 0.050 & - \\
\hline Euro 4 & Jan. 2006 & 0.50 & 0.30 & 0.25 & 0.025 & - \\
\hline Euro 5a & Sept. 2010 & 0.50 & 0.23 & 0.18 & 0.005 & - \\
\hline Euro 5b & Sept. 2011 & 0.50 & 0.23 & 0.18 & 0.0045 & $6 \times 10^{11}$ \\
\hline Euro 6b & Sept. 2015 & 0.50 & 0.17 & 0.08 & 0.0045 & $6 \times 10^{11}$ \\
\hline Euro 6d Temp & Sept. 2018 & 0.50 & 0.17 & 0.08 & 0.0045 & $6 \times 10^{11}$ \\
\hline Euro 6d & Jan. 2021 & 0.50 & 0.17 & 0.08 & 0.0045 & $6 \times 10^{11}$ \\
\hline
\end{tabular}

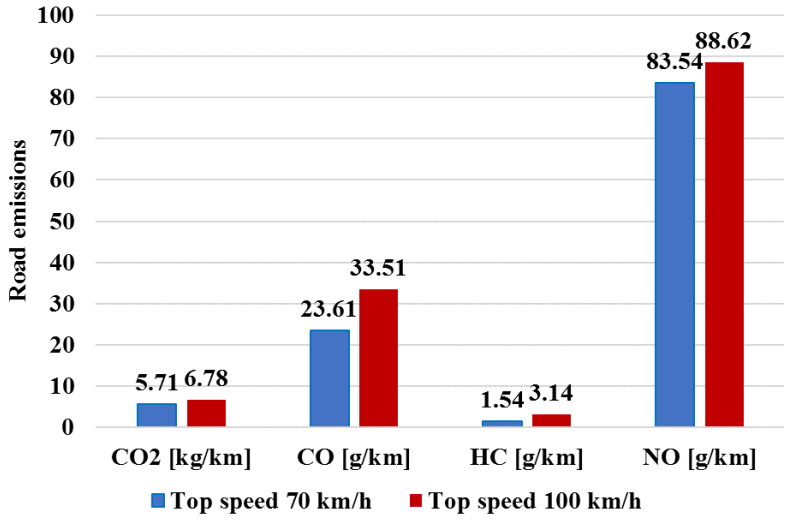

Fig. 6. Road emission values for test Drives 1 and 2.

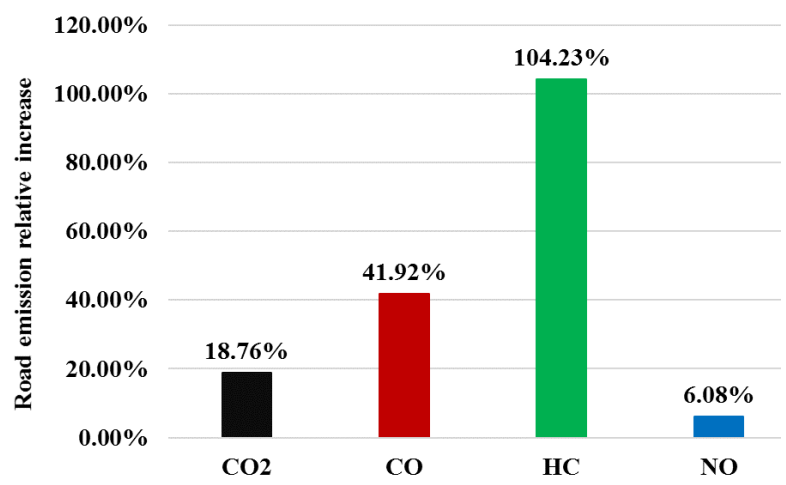

Fig. 7. Relative increase of road emission value for each of the measured exhaust components between Drive 1 and 2 .

The exhaust emission value in grams per passenger per kilometer was shown to be higher than for passenger cars meeting the Euro norms (Fig. 8). It should be noted that the LINK motor coach did receive type approval as meeting the EURO III B exhaust emission norms for heavy-duty diesel engines, which are given in $\mathrm{g} / \mathrm{kWh}$. The obtained data can therefore be used to clearly show the differences in specific and road emission values, that stem from the different methods of calculation.

The obtained results indicate a high road emission values for nitrogen oxides with a relatively low fraction of hydrocarbons. Hydrocarbon emission was also most affected by the increase in top travel speed during the test. The increase in the share of vehicle acceleration in the test drive cycle did not result in a significant increase of nitrogen oxide emissions. The increase of carbon dioxide emission, however, was over $18 \%$, which directly correlates with the vehicle fuel consumption. It was observed that the increase of top travel speed did not significantly reduce the total drive duration, with the mean travel speed for Drive 1 being equal to $25.67 \mathrm{~km} / \mathrm{h}$ and for Drive 2 at $32.08 \mathrm{~km} / \mathrm{h}$.

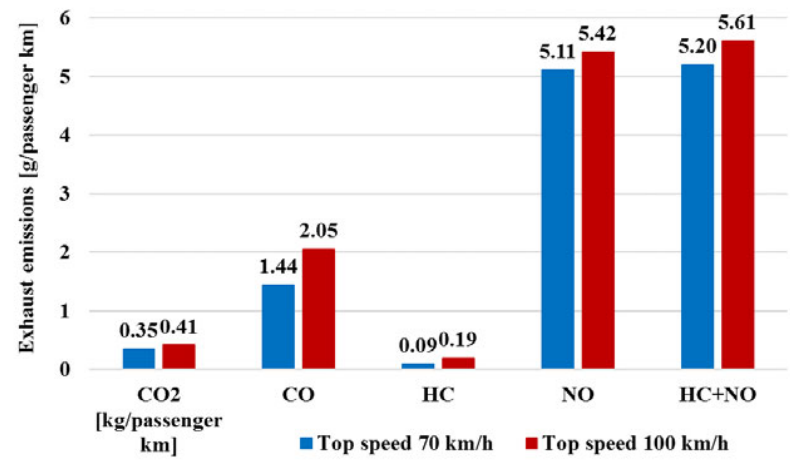

Fig. 8. Road emission values per passenger for test Drives 1 and 2 .

\section{Conclusions}

The overall exhaust emission values were determined according to the measured emission data for the four main exhaust components $\left(\mathrm{CO}_{2}, \mathrm{CO}, \mathrm{HC}, \mathrm{NO}\right)$. The European Environmental Agency claimed that the emission of carbon dioxide per passenger kilometer for rail transport is lower than for road transport or aviation (Fig. 9). This, however, does not take into account the toxic exhaust components contribution from each transport sector [6]. In order to properly represent the environmental costs of transport it becomes necessary to not only adjust the testing methods to be more representative (such as with the use of RDE tests), but also to provide a comprehensive assessment of real emission value for each toxic exhaust component per a 
single passenger being transported one kilometer. The use of specific emission values based on generated power allow an easier comparison of transport costs for goods and freight, but their accuracy in indicating the most environmentally friendly transport solution for passenger transport is questionable. Additional information could be used to improve the accuracy of the data comparison, such as the environmental and monetary costs of infrastructure, energy, maintenance, employment etc. It should be considered that the proper choice of maintenance procedures can have a significant impact on the lifelong environmental and economic impact of vehicles. There have been numerous attempts at quantitatively assessing the environmental and operating costs of public transport specifically [7], but the scope of assessment is limited by the comparability of the available data.

In terms of the method used it becomes clear that lowering the travel speed for rail vehicles results in lower exhaust emissions, mostly as a result of lower acceleration values. This allows the combustion engines to avoid operating in intermediate states with high load where their fuel efficiency and ecological indicators are not optimal. There is, however, a limit to how environmentally friendly a reduction in travel speed is, simply due to the vehicles still generating emissions even when at idle.

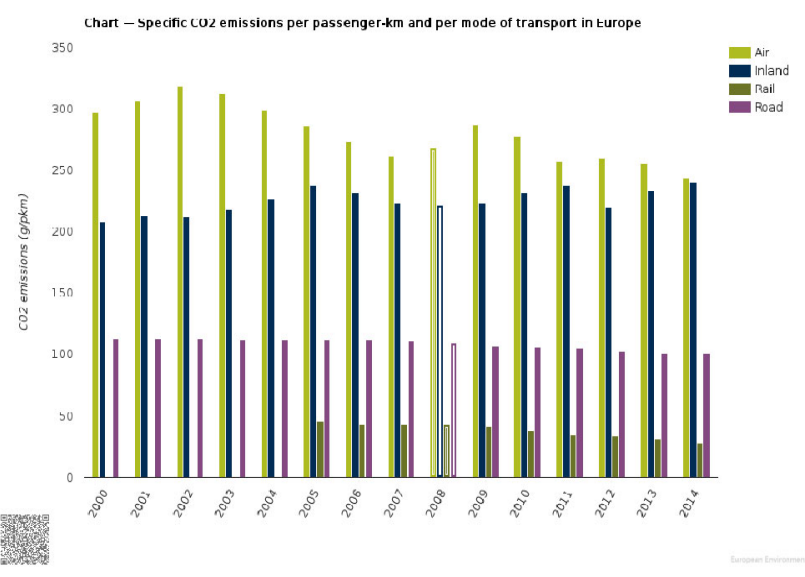

Fig. 9. Specific $\mathrm{CO}_{2}$ emissions per passenger-km for different modes of transport [8]

The proportion of power used by the engines to move the cargo or passengers needs to be sufficiently higher from the proportion used just to overcome the internal resistances of the engine and generate the power to sustain auxiliary vehicle systems. Additionally, the economic limits of lowering travel speed are significant for rail operators. Since the single largest cost of operating a train line is the staff wages, reducing the number of manhours required to safely perform one full trip has a significant impact on the profitability of a given transport operation [9].

In the obtained results it was found that the overall transport cost for a motor coach is relatively high in the chosen setup and method. Reaching at minimum 350 $\mathrm{g} / \mathrm{pkm}$ of $\mathrm{CO}_{2}, 1.44 \mathrm{~g} / \mathrm{pkm}$ of $\mathrm{CO}, 0.09 \mathrm{~g} / \mathrm{pkm}$ of $\mathrm{HC}$, and $5.11 \mathrm{~g} / \mathrm{pkm}$ of NO. This does not compare as favorably to road transport. It also indicates the importance of using an accurate method of establishing such values. Considering the data in Fig. 9 claimed by EEA it is not clear whether the $\mathrm{CO}_{2}$ emission value was established with proper consideration of the share of electric rail vehicles in the total number of transported passengers. Nor is it clear whether the environmental costs of generating electricity used to power those vehicles was taken into account. This leads to data sets that can be used only in a narrow context and can be misleading when used out of its intended context.

From the presented results it can be concluded, that the environmental efficiency of rail transport might be overestimated in the official data, and that it may be more comparable with road transport depending on the circumstances. This, in turn, indicates the continued need for improving both the exhaust emissions measurement and assessment methods, as well as new exhaust aftertreatment technologies for rail transport.

\section{References}

1. P.W. Park, M. Downey, D. Youngren, C. Bruestle, ASME 2012, Internal Combustion Engine Division, Vancouver, Canada. ICEF2012-92198, pp. 591-600, doi:10.1115/ICEF2012-92198 (2012)

2. A. Merkisz-Guranowska, M. Andrzejewski, P. Daszkiewicz, D. Gallas, H. Stawecka, Pojazdy Szynowe 3 (2016).

3. M. Bajerlein, L. Rymaniak, P. Swiatek, A. Ziolkowski, P. Daszkiewicz, M. Dobrzynski, Applied Mechanics and Materials 2014, Volume: 518, Pages: 108-113 (2014) DOI: $10.4028 /$ www.scientific.net/AMM.518.108

4. L. Rymaniak, MATEC Web of Conferences, Volume: 118 (2017) Article Number: UNSP 00009, DOI: $10.1051 /$ matecconf $/ 201711800009$

5. L. Rymaniak, P. Daszkiewicz, J. Merkisz, Y.V. Bolzhelarskyi, AIP Conference Proceedings, 2078 (2019)

6. European Environmental Agency (EEA) data transport emissions of air pollutants https://www.eea.europa.eu/data-andmaps/indicators/transport-emissions-of-airpollutants-8/transport-emissions-of-air-pollutants-6

7. K. Andrzejczak, J. Selech, TRANSPORT PROBLEMS, Volume: 12, Issue: 3, Pages: 103-111, 2017. DOI: $10.20858 /$ tp.2017.12.3.10

8. European Environmental Agency (EEA) data specific $\mathrm{CO}_{2}$ emissions per passenger chart https://www.eea.europa.eu/data-andmaps/daviz/specific-co2-emissions-per-passenger3\#tab-chart_1

9. European Commission Directorate General for Mobility and Transport - Study on the prices and quality of rail passenger services - Final Report 2016 by Steer Davies Gleave. 